\title{
An Investigation of the Role of Explicit and Implicit Instruction in Second Language Acquisition: A Case of English Embedded Question
}

\author{
Manoochehr Jafarigohar \\ Department of Foreign Languages and Literature, Payame Noor University, Iran \\ PO box 19395-4697, Tehran, IR. Iran \\ E-mail: jafarigohar.2007@yahoo.com \\ Fatemeh Hemmati \\ Department of Foreign Languages and Literature, Payame Noor University, Iran \\ PO box 19395-4697, Tehran, IR. Iran \\ E-mail: fatemehhemmati2002@yahoo.co.uk \\ Hassan Soleimani \\ Department of Foreign Languages and Literature, Payame Noor University, Iran \\ PO box 19395-4697, Tehran, IR. Iran \\ E-mail: arshia.soleimani@gmail.com \\ Mehri Jalali (Corresponding Author) \\ Department of Foreign Languages and Literature, Payame Noor University, Iran \\ PO box 19395-4697, Tehran, IR. Iran \\ E-mail: mehrijalali2013@yahoo.com
}

Received: 24-09- 2014

Published: 01-05- 2015
Accepted: 13-12- 2014

doi:10.7575/aiac.ijalel.v.4n.3p.98
Advance Access Published: December 2014

URL: http://dx.doi.org/10.7575/aiac.ijalel.v.4n.3p.98

\begin{abstract}
The present study examined the facilitative effects of three types of input-based (explicit and implicit) instruction on the intake and acquisition of the English embedded questions. The participants were 105 Iranian EFL learners from four intact classes who were randomly assigned to three treatment groups of processing instruction (PI), consciousnessraising tasks (C-R), textual input enhancement (TE), and one control group (CO). A quasi-experimental design with a pretest-treatment-posttest (immediate and delayed) sequence was used. Assessment consisted of a grammar knowledge test which included interpretation and production tasks at sentence level and a timed grammaticality judgment test. The results of data analysis indicated that all treatment groups performed significantly better than the control group on the interpretation tests over time and the treatments were also effective in improving the intake of the target structure measured through grammaticality judgment test. Moreover, all types of instruction were effective in improving the learners' production tests except the TE. Since PI was superior to other groups in all of the tests one reasonable pedagogical implication is that explicit instruction is a more effective technique in helping EFL learners to acquire target grammatical forms.
\end{abstract}

Keywords: Consciousness-raising tasks, Processing instruction, Sentence location principle, Textual input enhancement

\section{Introduction}

The positive role of instruction in Second Language Acquisition (SLA) has long been a controversial issue. This debate takes place at two fundamental levels. At first level, some theorists (e.g., Krashen, 1985) assert that instruction can have no consequence away from the provision of an environment helpful to SLA. At second level, some other scholars (e.g., Doughty \& Williams, 1998) have made a case in favor of instruction. They claim that while there is a common recognition that much of the second language (L2) can be learnt naturally, there are certain linguistic features that cannot be acquired by L2 learners except they receive instruction. Then, assuming the inevitability of appropriate instruction, some researchers (e.g., Green \& Hecht, 1992) have studied the comparative effectiveness of different types. An essential question in this regard is whether the most effective instruction is implicit or explicit and in what ways learners' attention should be directed to the elements of language. Doughty and Long (2003) define explicit instruction as "all types of instruction in which rules are explained to learners, or when learners are directed to find rules by attending to forms" (p. 256). Conversely, implicit instruction makes no overt reference to rules or forms and engages language learners in different communicative activities that will trigger natural acquisitional processes (Scheffler \& Cinciała, 2010). 
So far, many studies have identified a significant role for explicit instruction in SLA (e.g., Ellis, 1993; Hernández, 2011) and have stated that it promotes noticing and subsequent intake of the target forms. In direct contract to these conclusions, however, a number of empirical research (Morgan-Short, Sanz, Steinhauer, \& Ullman, 2010; Sanz \& Morgan-Short, 2004) indicate that explicit instruction is not a significant contributor to SLA. Given that the effectiveness of explicit or implicit instruction still remains in question, this study has investigated the comparative effectiveness of three input-based instructional treatments, namely processing instruction (PI), consciousness-raising tasks (C-R), and textual input enhancement (TE) that differ in their degree of instructional explicitness.

\subsection{Processing Instruction}

Processing instruction (PI) is a new explicit instructional approach (VanPatten, 2004) looks for promoting the creation of form-meaning connections by means of input-based activities that are task-essential (Loschky \& Bley-Vroman, 1993 ) in the sense that successful task completion requires connecting target forms and meanings in appropriate ways. In fact, PI aims to improve the quality of the input received by learners so that the amount of intake will increase. According to Reinder and Ellis (2011), "intake is a subset of the detected input (comprehend or not), held in short-term memory, from which connections with long-term memory are potentially created or strengthened" (p. 73).

In fact, PI has three main components: explicit information about a linguistic form, information about the faulty processing strategies and structured input activities. A key feature of information about the faulty processing strategies is pointing out to learners the suboptimal first-language (L1) strategies they tend to use during L2 processing. The most important component of PI - structured input activities - is designed in order to direct learners' attention to what are often less prominent, more complex features of the L2 so that they are detected and processed in ways that help formmeaning connections. According to Neupane (2009), there are two kinds of structured input activities: referential (those for which there is a right or wrong answer) and affective (those for which learners are engaged in processing information about the real world). In both of these activities any production of the target grammatical forms is not necessary due to their input-based nature.

VanPatten and Cadierno (1993a) were the first investigators who compared the effects of PI with traditional instruction on the development of Spanish preverbal direct object pronouns by second-year Spanish students. Findings revealed that on the interpretation test, the PI group performed significantly better than the traditional group and the control group. However, for the production test, there was no significant difference between the performances of the experimental groups but both of them had better performance than the participants in the control group.

Later, Cadierno (1995) attempted to measure the probable effects of PI on learning Spanish preterit tense. Participants were randomly divided into three groups: PI group, TI group, and control group and results showed that PI group outperformed the other groups from the pretest to the posttest. However, the results of the production tasks revealed that there weren't any significant differences between PI and TI groups in production test scores and both groups performed better than control group in these tasks.

On the other hand, some researchers (e.g., Farley, 2001; Benati, 2001) compared PI with meaningful output-based instruction. Farley (2001) compared PI with meaningful output-based instruction on the development of subjunctive form in Spanish. Results showed that learners who received PI scored higher than the other groups on interpretation tasks. Surprisingly, like the results of other studies in the PI strand that had used TI as a grammar instruction approach (e.g. Benati, 2005, VanPatten \&Wong, 2004); findings of this research couldn't find any significance difference between the mean scores of both groups on production posttests (immediate and delayed).

Moreover, some other studies (e.g., Henry, Culman, \& VanPatten, 2009; Staford, Bowden, Sanz, 2012; VanPatten \& Oikenon, 1996) have compared the components of PI to find the most helpful one. The first research that tried to deal with this issue carried out by VanPatten and Oikenon (1996). These researchers selected the Spanish direct object pronouns as their target structures and employed an experimental research design with three treatment groups: (a) full PI group, (b) explicit grammar explanation only group (EI), and (c) referential structured input activities only group (SI). Results revealed that the performance of the full PI and the SI groups on interpretation tasks improved similarly from pretests to posttests, while the EI group did not make any gain. Likewise, the results showed that the scores of the full PI and the SI groups on the production tasks were higher than those of the only EI group. As a result, the researchers concluded that structured input activities were responsible for learning the target forms by learners through making form-meaning connections. They also stated that the explicit explanation is a necessary component of PI. This conclusion was maintained by some of the next studies (e.g., Benati, 2004; Wong, 2004).

\subsection{Consciousness-Raising tasks}

As an approach to grammar instruction, the goal of consciousness-raising tasks (C-R) is to obtain explicit knowledge of target features. According to Ellis (1997), these tasks provide L2 data for learners and they should perform some operations on or with them to arrive an explicit understanding of some linguistic properties of the second language. In fact, these tasks attempt to raise the learners' awareness of grammatical features at the level of understanding and do not force them to produce them (Sugiharto, 2006). C-R tasks are often claimed to hold a middle-ground position between two extreme approaches to teaching grammar (Yip, 1994). In order to show this position, Yip (1994) points to a scale which the Zero approach (no need for instruction) is located at one end of this scale and at the other end is traditional grammar-based approach (explicit instruction). According to Ellis (1997), the main features of C-R tasks are as follows:

1. There is an attempt to isolate a specific feature for focused attention.

2. The learners are provided with data that illustrate the target feature.

3. The learners are expected to utilize rule describing or explaining the feature.

4. Learners may be optionally required to verbalize a rule describing the grammatical structure (p. 163). 
Fotos and Ellis (1991) were the first persons who attempted to find possible effectiveness of direct and indirect C-R tasks in development of grammatical knowledge. Results revealed that both methods of consciousness-raising were effective in understanding the dative alternation by Japanese learners of English with more durable gains made by participants exposed to the direct method. Later, Fotos (1994) replicated this study and results again showed that there was no significant difference between the two groups. On the other hand, Amiran and Sadegi (2012) compared the traditional approach in grammar instruction with C-R tasks. The results were compared with those of a control group that was taught based on the pattern drill practice and traditional approaches. Findings showed that using C-R tasks in grammar teaching is significantly more effective than the traditional approach. In addition, Takimoto (2012) compared the effects of C-R tasks with a more implicit approach namely input enhancement (IE) on the development of speech act of apology by Japanese university students. The results of the multiple-choice discourse completion task indicated that learners in the C-R group outperformed those in the IE group and the control group on both immediate and delayed posttests.

\subsection{Textual Input Enhancement}

Input enhancement is a theory-based language teaching approach proposed by Sharwood Smith (1991). He defines it as "any pedagogical intervention that is used to make specific features of L2 input more salient as an effort to draw learners' attention to these features" (p. 119). Textual enhancement (TE) is an implicit input enhancement technique used to expand the saliency of the new target form(s) and as Simard (2009) asserts, it attempts to draw learners' attention to linguistic features through typographical cues like, underlining, boldfacing, italicizing, capitalizing, highlighting, and changing the size or the font of the letters.

There are different research paradigms in the TE domain. For example, in some investigations textually enhanced texts have been compared with other types of instruction such as explicit instruction and different types of output-based tasks. Some researchers have attempted to compare different techniques of TE especially underlining, italicizing, and boldfacing. However, the results on the usefulness of TE are contradictory. Findings of some studies are in favor of the TE (e.g., Doughty, 1991; Wong 2004), whereas some other studies have demonstrated no positive effect for it (e.g., Lee, 2007; Overstreet, 1998). Moreover, results of some other studies show a minimum effect for this input enhancement technique (e.g., Ellis, Loewen, \& Erlam, 2006; Izumi, 2003; Sanz \& Morgan-Short, 2004).

Doughty (1991) studied the effects of two kinds of comprehension-based instruction on the acquisition of English relative clauses. Participants were divided into two groups: meaning oriented group (MOG) and rule oriented group (ROG). During the treatment session, participants in the MOG group received textually enhanced passages. They were also exposed to lexical and semantic rephrasing of the relative clauses to make their meaning clear. Participants in the ROG group received the same texts which were enhanced through animation of the sentences. In addition, they had an extra treatment including the explicit explanation about the target rules. Control group was only exposed to unenhanced passages. Results showed the superiority of both experimental groups over the control group in acquisition of the target form. Doughty, concluded that TE and its combination with explicit instruction also could lead to the intake of the selected target structure.

In contrary to Doughty's findings, the results of Overstreet's (1998) research did not support the positive effects of TE on learning grammatical structures. Overstreet found that presence of TE might actually hinder L2 learners' comprehension of target forms. Moreover, text familiarity did not appear to facilitate the acquisition of the target forms. On the other hand, Izumi (2003) examined the probable efficiency of TE (bold, shadowed, different font, different font size) on noticing and learning of relative clauses by adult learners of English as a second language. To assess noticing, he used the notes participants took as they were exposed to the experimental treatment. Results showed that although the tasks were useful in promoting the noticing of the target forms, no learning gains from the pretest to the posttest were observed.

\section{The Present Study}

In sum, although most of the previous research in PI paradigm support the superiority of this kind of explicit instruction in teaching grammar, some investigations in this field (e.g., Collentine, 2004; Salaberry, 1997) have been criticized in different ways like using measurement tasks which assess learners' comprehension of the input passage instead of measuring input processing of the selected linguistic features. Few studies also have compared PI with other kinds of input-based instruction (Lee \& Benati, 2007). Moreover, as VanPatten (1996) has mentioned, one of the main purpose of PI is to improve the amount and quality of the intake derived from input; however, it seems that measuring intake is a missing part in most of the studies in this strand. Therefore, to expand the scope of the PI study the current study attempted to compare it with less explicit (C-R) and implicit (TE) grammar instructions. The present study was aimed at answering the following questions:

1. Is there any significant difference among the study groups (PI, C-R, TE, CO) in the acquisition of the English embedded questions as measured by interpretation tests over time?

2. Is there significant difference among the study groups (PI, C-R, TE, CO) in the acquisition of the English embedded questions as measured by production tests over time?

3. Is there significant difference among the study groups (PI, C-R, TE, CO) in the intake of the English embedded questions as measured by timed grammaticality judgment tests? 


\section{Method}

\subsection{Participants}

One hundred and five male and female students from four intact General English classes in one of the universities in Iran participated in this study. Their first language was Persian and they had studied English from 6 to 7 years with the age range of 19 to 35. After checking applicants' scores on the Cambridge language proficiency test (PET), only preintermediate English proficiency level learners were selected for inclusion in the study. Then, classes were randomly assigned to one of the four groups consisting of three treatment groups: the PI ( $n=30), C-R(n=22)$, and the TE $(n=28)$ and the control group $(\mathrm{CO}, \mathrm{n}=25)$.

\subsection{Target Structure}

Sentence Location Principle is one of the sub-principles in VanPatten's (1996) model of Input Processing. According to this principle, elements that appear in sentence initial position are more salient than those occur in sentence final position and the least salient is sentence medial position. Therefore, the selected structure for this study was English embedded question since most of the Persian learners of English consider it as ordinary type of question and invert the place of auxiliary and subject after "WH" question word. It is noteworthy that Yes-No indirect questions were not focused in this study.

\subsection{Instructional Treatments}

Each teaching session for the three treatment groups and the control group lasted for 90 minutes. The teaching sessions were conducted once weekly for three weeks by the same instructor and she gave all directions in Persian during the instruction. The three instructional treatments were matched for the target structure and the amount of instructional time. Learners in each class were divided into small groups of four to five members to do the activities cooperatively. All treatment groups received implicit feedback and correct answers were not provided if participants answered incorrectly in order to avoid providing them with incidental input.

\subsubsection{Processing Instruction}

The PI treatment consisted of three components which were adapted directly from the pen-and-paper instructional package used by VanPatten and Cadierno (1993b): (a) non-paradigmatic grammatical explanation about English embedded questions, (b) information about the sentence location processing strategy, and (c) structured input activities. In order to design these activities, four short stories including samples of the target structure which matched the participants' language proficiency level were selected. Since moving from sentences to connected discourse is one of the guidelines for designing these activities, stories were divided into separate sentences. Combination of these sentences could make connected discourse at the end of the tasks for reading comprehension purpose. The referential and affective activities were structured so that target structure had to be interpreted in order to complete them and no practice activity required the production of the target form (see Appendix A). In each lesson, handouts containing structured input activities and reading comprehension passage with multiple choice questions were given to the small groups. After answering the questions of all three parts, the leader of each group was asked to present the answers to the whole class.

\subsubsection{Consciousness-Raising Tasks}

The C-R treatment also consisted of three components: (a) reading comprehension passage, (b) making formcomparisons in a table, and (c) writing the rule describing the target feature. In each lesson, learners were given the same stories used for the PI group. After reading the passages, participants were asked to read the story and answer its question. Then, they could complete a table with three columns. It consisted of correct samples of the target structure in the first and incorrect ones in the second column. The participants were supposed to compare the correct and incorrect samples and explain (in their mother tongue) why some of the samples were incorrect in the space provided in the third column (Appendix B). All of these sentences had been extracted from the stories so that the learners could compare the incorrect sentences with their correct equivalent in them. Finally, they were asked to provide a metalinguistic explanation for the rule related to the embedded questions.

\subsubsection{Textual Input Enhancement}

The instructional treatment used for the TE group included the same stories used for the other experimental groups, while the samples of the target structure were bolded and underlined. However, participants in this group first received the stories without any enhancement following by some multiple choice reading comprehension questions. Then, they received the enhanced input following by some multiple-choice interpretation questions similar to those used in the PI group. In this way, it was tried to prevent comprehension of the passages make any hindrance in paying attention to the enhanced parts. In other words, the sequential and not the simultaneous input enhancement technique was used (see Appendix B). This group didn't receive any instruction related to the target structure and they could only receive an immediate feedback regarding the accuracy of their responses.

\subsubsection{Control Group}

Lessons for the control group were designed to help participant do well on reading comprehension skills and they engaged in reading comprehension exercises of their textbook. They were not exposed to the target structure at all. 


\subsection{Testing Instruments}

In order to assess the acquisition of the target structure, a knowledge test including an interpretation and a production subtest was created in three parallel forms which were counterbalanced for order of presentation. Three versions had the same difficulty level (A, B, C) used as pretest, immediate posttest, and delayed posttest, in this way any test learning effect or test order effect would be minimized. The pretest was administered one week before starting the instruction, the immediate posttest was administered in the last session of the treatment, and the delayed posttest was administered one month later.

\subsubsection{Interpretation Test}

The interpretation test consisted of 25 mini dialogs ( 20 in form of embedded questions and 5 in form of direct questions which served as distractors). The participants received 1 point for the correct answers and 0 points for the incorrect ones (with maximum score of 20).

\subsubsection{Production Test}

A written completion test was developed to measure learners' ability to produce embedded questions. It consisted of 13 mini dialogs (3 items were dedicated to distractors which were direct questions) in which students were supposed to complete their summaries by using the words (four words) provided in brackets properly. The raw score was calculated by giving 1 point to fully correct answer, 0.25 point for using each of the elements properly, and zero point if no element was used correctly (with maximum score of 10). In fact, this tolerant scoring procedure was used, as in previous investigations, to reveal any partial effects of instruction.

\subsubsection{Timed Grammaticality Judgment Test}

The timed grammaticality judgment test was used to measure intake of the target structure. It was in form of two parallel tests (A, B), with test A as the pretest, and test B as the immediate posttest. Each test consisted of 20 sentences including 15 items dedicated to the target structure and 5 items dedicated to the distractors. Participants received one point for each correct answer. The tests were timed because according to Reinders and Ellis (2009), in grammaticality judgment tests, giving too little time will obviously impair understanding, whereas giving too much time risks allowing participants to reflect on the sentences. The time limitation was determined through piloting the tests with learners who had characteristic similar to those of the participants. The pretest was administered one week before the first session of the treatment and the posttest was administered immediately after the first session of the treatment. As Rosa and O'Neill (1999) pointed out, if recognition measures are used for measuring intake, they should be administrated immediately after the exposure to the target features.

3.4.4 Language Proficiency Test

Cambridge language proficiency test (PET) used to ensure the homogeneity of the groups regarding their language knowledge. Based on the results of this test, participants were set at the pre- intermediate level of language proficiency. It was administered before the pretests.

\subsection{Validity and Reliability}

In order to validate content of the tests, the original pool of items was reviewed by three foreign language teaching experts. Some items were either eliminated or modified based on their comments and the remaining items were trialed on 15 pre intermediate-level learners with characteristics similar to characteristics of participants in the main study to examine the item characteristics and reliability of the tests. Cronbach's alpha indexes were $.84, .89$, and .81 for the interpretation subtest in forms $\mathrm{A}, \mathrm{B}$, and $\mathrm{C}$ respectively and $.88, .83$, and .86 for the forms $\mathrm{A}, \mathrm{B}$, and $\mathrm{C}$ of the production subtest. Moreover, KR20 analyses were performed to estimate participants' response consistency across two versions of the grammaticality judgment test and the estimated values were 0.91 , and 0.88 respectively.

\section{Results}

\subsection{Results From Interpretation Test}

The results of a one-way ANOVA with repeated-measures performed on the raw scores of this test revealed a significant main effect for type of instruction (PI, C-R, TE, and CO groups), $F(3,101)=121.58, p=.000$, a significant main effect for time (pretest, immediate posttest, and delayed posttest), $F(2,101)=140.32, p=.000$, and a significant interaction effect between instruction and time, $F(6,101)=65.64, p=.000$ (Table 1). The significant interaction effect between instruction and time on the interpretation test items in Fig. 1 were moderated by those of time. Even though all groups had similar means on the pretests, $F(3,101)=1.45, p=.233$, there was a sharp increase in scores from the pretests, to the immediate posttests for the three treatment groups and a significant main effect for instruction on the immediate posttests and the delayed posttests, $F(3,101)=73.45, p=.000$. Post-hoc Scheffé tests conducted on the immediate posttests and delayed posttests scores for the main effect of the treatment revealed these contrasts $(p<.05)$ : the treatments had significant effects on interpretation of the target form by the PI, the C-R, and the TE groups compared to the control group. There were significant differences among the treatment groups ( $\mathrm{PI}>\mathrm{C}-\mathrm{R}>\mathrm{TE}$ ). In addition, the positive effects of the three kinds of treatment were maintained from the immediate posttests to the delayed posttests. In short, the effects of instruction were larger on the immediate posttest and the delayed posttest than on the pretest and the interaction revealed a great superiority of the treatment groups over the control group. 
Table 1. Analysis of variance for interpretation test scores

\begin{tabular}{lccccc}
\hline \multicolumn{1}{c}{ Source } & $S S$ & $d f$ & $M S$ & $F$ & Sig \\
\hline $\begin{array}{l}\text { Between Subjects } \\
\text { (Instruction) }\end{array}$ & 518.01 & 3 & 172.67 & 121.58 & .000 \\
Within Subjects (Time) & 650.80 & 2 & 825.40 & 140.32 & .000 \\
Instruction $\times$ Time & 773.43 & 6 & 128.90 & 65.64 & .000 \\
\hline
\end{tabular}

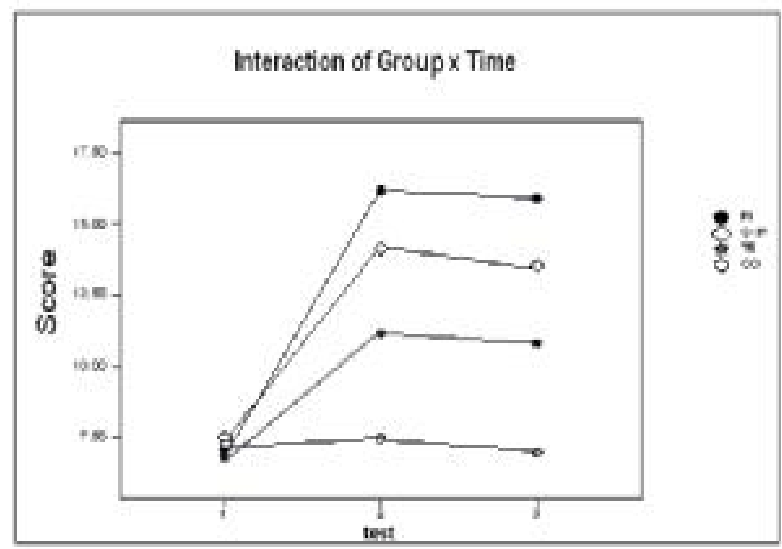

Figure 1. Interaction Plot for Instruction Type and Time for Interpretation of the Embedded “WH” Questions

\subsection{Results From Production Test}

The results of a one-way $A N O V A$ with repeated-measures conducted on the raw scores of this test revealed a significant main effect for type of instruction (PI, C-R, TE, and CO groups), $F(3,101)=64.42, p=.000$, a significant main effect for time (pretest, immediate posttest, and delayed posttest), $F(2,101)=80.78, p=.000$, and a significant interaction effect between instruction and time, $F(6,101)=30.09, p=.000$ (Table 2). The significant interaction effect between instruction and time on the production test items in Fig. 2 were moderated by those of time. Although all groups has similar means on the pretests, $F(3,101)=1.14, p=.33$ there was an increase in scores from the pretests, to the immediate posttests for the PI and C-R groups and a significant main effect for instruction on the immediate posttests and the delayed posttests. Moreover, results of Post-hoc Scheffé tests provided further support for the following contrasts: $(p<.05)$ : The treatments had significant effects on production of the target form by the PI and the C-R groups compared to the TE and the CO groups. There were significant differences between these groups (PI $>\mathrm{C}$-R). In addition, the positive effects of the PI and the C-R were maintained from the immediate posttests to the delayed posttests. In short, the effects of PI and C-R treatments were greater on the immediate posttest and the delayed posttest than on the pretest and the interaction revealed a great superiority of these groups over the TE and CO groups. Therefore, textual enhancement was not an effective treatment in improving production of the embedded questions.

Table 2. Analysis of variance for production subtest scores

\begin{tabular}{lccccc}
\hline Source & $S S$ & $d f$ & $M S$ & $F$ & Sig \\
\hline Between Subjects & 139.07 & 3 & 46.36 & 64.42 & .000 \\
(Instruction) & & & & & \\
Within Subjects (Time) & 160.30 & 2 & 86.06 & 80.78 & .000 \\
Instruction $\times$ Time & 379.12 & 6 & 29.85 & 30.09 & .000 \\
\hline
\end{tabular}

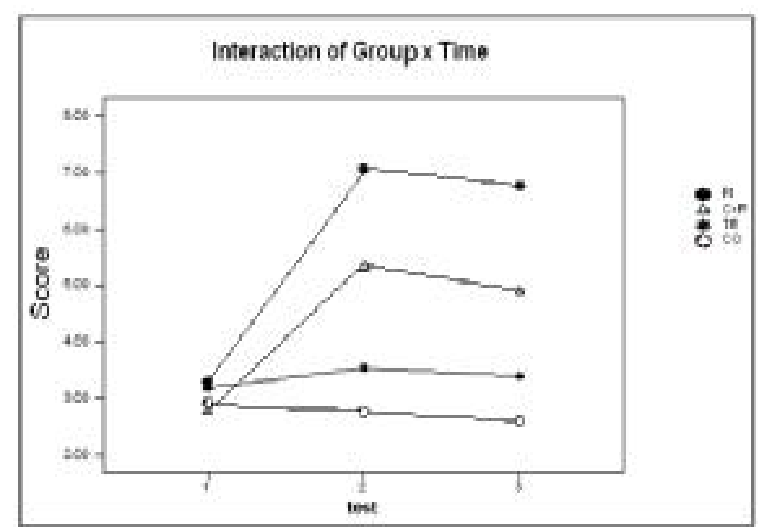

Figure 2. Interaction Plot for Instruction Type and Time for Production of the Embedded "WH” Questions 
4.3 Results From Grammaticality Judgment Test

The results of a one-way $A N O V A$ conducted on the raw scores of this test revealed no significance difference between the groups regarding their knowledge of this structure before starting the treatment $(p<.05), F(3,101)=3.88, p=.24$. However, the results of a one-way $A N O V A$ conducted on the posttest scores revealed a significant difference in the intake of English embedded questions among the study groups, $F(3,105)=73.51, p=.000$ (Table 3). Post-hoc Scheffé tests conducted on the immediate posttests and the delayed posttests scores revealed these contrasts $(p<.05)$ : although all instructional treatments were effective in improving the intake of this target form, there were differences between the amount of the improvement $(\mathrm{PI}>\mathrm{C}-\mathrm{R}>\mathrm{TE}>\mathrm{CO})$.

Table 3. Result of One-way ANOVA for timed grammaticality judgment posttest scores

\begin{tabular}{lccccc}
\hline & $\begin{array}{c}\text { Sum of } \\
\text { Squares }\end{array}$ & df & Mean Square & F & Sig \\
\hline Between Groups & 109.73 & 3 & 336.57 & 73.51 & $* .000$ \\
Within Groups & 462.39 & 101 & 4.57 & & \\
Total & 672.13 & 104 & & & \\
\hline
\end{tabular}

\section{Discussion}

Research question 1 asked about the differential performance of the PI, C-R, TE, and CO groups on interpretation of the English "WH" embedded questions over time. The results of this study indicate that in comparison to the control group, all of the treatments were effective and their positive effects were maintained after one month. Moreover, results showed a significant difference between groups' means in interpretation tests (PI $>C-R>T E)$.

These findings support results of past studies in the PI strand which compared PI with other grammar instruction approaches and found PI superior to other input-based treatments for interpretation tasks (Benati, 2001; VanPatten \& Cadierno, 1993b). On the other hand, effects of consciousness-raising tasks on interpretation of the target structures are in agreement with the results obtained by some studies (Abdolmanafi, 2010; McNicoll \& Lee, 2011) that confirmed the positive impacts of C-R tasks on enhancing learners' structural knowledge. Regarding TE, results confirm the findings of those investigations that have reported the significant effects of input enhancement techniques like, boldfacing and underlining on recognizing the target structures (Doughty, 1991; Trahey \& White, 1993).

The second research question investigated whether there was significant differential performance between the study groups for production of the embedded "WH" questions. Results showed that both PI and C-R tasks were effective in improving the production of the target structure and they maintained their effect through time. However, the mean scores of the PI group were significantly higher than the means scores of the C-R group in both immediate and delayed posttests. Moreover, results showed that exposure to the TE instruction didn't have beneficial effect on learners' ability to produce the embedded "WH" questions and control group had no gain in these tests. These results show parallels with findings of some studies like, Lee and Benati (2007), and VanPatten and Uludag (2011) that provided some evidence for superiority of PI to other kinds of grammar instruction such as input enhancement and no instruction on a written completion task at sentence level. However, there are some investigations that reveal the opposite results. For example, the findings of the studies done by Allen (2000) and Toth (2006) showed there was no advantage for PI over other grammar instructional approaches like input enhancement in fostering learners' interpretation and production of the target features.

The third research questions asked about the effects of the treatments on the intake of the target structure and results showed the significant effects of the instructional treatments in comparison to the control group. Again results confirmed the better performance of the PI group in grammaticality judgment test. This finding is in agreement with the finding of Rosa and O’Neill (1999) who showed that learners receiving explicit instruction manifested higher levels of intake than learners in the implicit instruction groups.

There are some non-exclusive reasons for the results of this study. One is the fact that the less implicit forms of instruction such as textual enhancement are not sufficient for trigging the necessary cognitive processes required for language performance to happen. Leow (1997) suggests that certain methodological considerations may clarify why implicit instruction does not give in the desired goals including: the levels of attention learners pay to the enhanced features, and the amount of exposure to the enhancement. Ellis (1993) also has presented the same argument that implicit instruction is often slow and difficult and usually needs longer time than explicit instruction in order to be effective. Therefore, the explicit information provided in the PI is effective in inducing changes in the learners' L2 ability.

As for the relationship between level of awareness and language learning, some scholars (e.g., Alanen, 1995; Robinson, 1997) believe that awareness at the level of noticing is not enough for language performance to occur. For progress in performance, awareness at the level of understanding is required and implicit instruction provides awareness at the level of noticing. This might be one of the possible reasons for lack of success in production of the embedded questions by the TE group in this study.

The effectiveness of the consciousness-raising task in promoting the interpretation and production of the target structure is related to the point that this form of more explicit input enhancement induced the participants' attention to form in the 
input by exposing the students to awareness enhancement. In order to distinguish target structures, they compared the correct and incorrect samples they received. To do so, they were supposed to read the texts more deeply to find the correct forms of the incorrect samples presented in the table. It seemed clear that the students' awareness improved by doing so. It is observed that focus on discovery learning improve the students' responsibility and autonomy because they themselves tried to make up the rules based on this comparison. Mohamed (2004) believes that C-R task is probable to gradually lead to the learners' conscious attention to the linguistic features as they have more opportunities to be exposed to metalinguistic information related to those features and more autonomy to discover the rules. This is in line with Mishan's (2005) argument that the rational of the C-R approaches is that given adequate exposure and opportunity, learners will discover elements of L2 grammar and this involves integration of their new finding with their current interlanguage. Therefore, applying this approach trains learners in techniques which they can then use to study independently.

Regarding the effectiveness of PI in improving the production of the target structures, VanPatten (2002) argues that PI provides the data through input, structured input activities makes the data available for acquisition in form of intake which in turn activates internal mechanisms accommodate data into the system in form of output.

\section{Conclusion}

The primary purposes of the present study were to examine the relative effects of three input-based instructions which were different regarding the degree of their explicitness on learning English embedded questions by Iranian EFL learners. The results can be useful for English teachers and curriculum developers especially in a foreign language context where learning English grammar has change into one of the most important areas of focus, and where exposure to English is limited and the amount of class time dedicated to teaching English is limited too.

The findings of this study show that input-based instructions can work when they provide explicit information on forms and meanings. In this regard, teachers may require examining different tasks they use in their lessons to see whether they provide learners with the chance for processing both forms and meanings of the target forms.

It should be pointed out, however, that there are several limitations in this study. Due to the participants' low language proficiency level, the production test was restricted to the sentence completion. Moreover, this research could be improved in future replications by investigating whether the instructional treatments could be delivered effectively online as well as in classrooms. In short, such studies would provide clearer guidelines for selecting methodological options for teaching grammar in EFL context.

\section{References}

Abdolmanafi, S. J. (2010). Effects of focus on form on the learning of relative clauses in an EFL context. MJAL, 2, 27-39.

Alanen, R. (1995). Input enhancement and rule presentation in second language acquisition. In R. Schmidt (Ed.), Attention and awareness in foreign language acquisition (pp. 259-302). Honolulu: University of Hawaii.

Allen, A. (2000). Form-meaning connections and the French causative: An experiment in input processing. Studies in Second Language Acquisition, 22, 69-84.

Amirian, M., \& Sadeghi, F. (2012). The effect of grammar consciousness-raising tasks on EFL learners performance. International Journal of Linguistics, 4(3), 708-720.

Benati, A. (2001). A comparative study of the effects of processing instruction and output based instruction on the acquisition of the Italian future tense. Language Teaching Research, 5(2), 95-127. Retrieved from http://ltr.sagepub.com/content/5/2/95

Benati, A. (2004). The effects of structured input activities and explicit information on the acquisition of the Italian future tense. In B. VanPatten (Ed.), Processing instruction: Theory, research, and commentary (pp. 207-226). Mahwah, NJ: Erlbaum.

Benati, A. (2005). The effects of processing instruction, traditional instruction and meaning- output instruction on the acquisition of the English past simple tense. Language Teaching Research, 9, 67-93.

Cadierno, T. (1995). Formal instruction from a processing perspective: An investigation into the Spanish past tense. Modern Language Journal,79, 179-193.

Collentine, J.G. (2004). Commentary: Where PI research has been and where it should be going. In B. VanPatten (Ed.), Processing instruction: Theory, research, and commentary (pp. 169-181). Mahwah, NJ: Erlbaum.

Doughty, C. (1991). Second language instruction does make a difference: Evidence from an empirical study of SL relativization. Studies in Second Language Acquisition, 13, 431-469.

Doughty, C., \& Long, M. (2003). The Handbook of Second Language Acquisition. Oxford: Blackwell. Doughty, C., \& Williams, J. (1998). Focus on form in classroom second language acquisition. Cambridge: Cambridge University Press.

Ellis, N. (1993). Rules and instances in foreign language learning: Interactions of implicit and explicit knowledge. European Journal of Cognitive Psychology, 5(3), 289-319.

Ellis, R. (1997). SLA research and language teaching. Oxford: Oxford University Press.

Ellis, R., Loewen, S., \& Erlam, R. (2006). Implicit and explicit corrective feedback and the acquisition of L2 grammar. 
Studies in Second Language Acquisition, 28, 339-369.

Farley, A. (2001). Authentic processing instruction and the Spanish subjunctive. Hispania, 84, 289-299.

Fotos, S. (1994). Integrating grammar instruction and communicative language use through grammar consciousnessraising tasks. TESOL Quarterly, 28, 323-351.

Fotos, S., Ellis, R. (1991). Communicating about grammar: A task-based approach. TESOL Quarterly, 25, 605-628. Green, P. \& Hecht, K. (1992). Implicit and explicit grammar: An empirical study. Applied Linguistics, 13, 168-84. Henry, N., Culman, H., \& VanPatten, B. (2009). More on the effects of explicit information in instructed SLA: A partial replication and a response to Fern'andez (2008). Studies in Second Language Acquisition, 31, 559-575. Hernandez, T. A. (2011). Re-examining the role of explicit instruction and input flood on the acquisition of Spanish discourse markers. Language Teaching Research, 15(2) 159-182.

Izumi, S. (2003). Processing difficulty in comprehension and production of relative clauses by learners of English as a second language. Language Learning, 53, 285-323.

Krashen, S. (1985). The input hypothesis: Issus and implication. WY: Longman.

Lee, S. (2007). The effects of textual enhancement and topic familiarity on Korean EFL students' reading comprehension and learning of passive form. Language Learning, 57, 87-118.

Lee, J., \& Benati, A. (2007). Delivering processing instruction in classrooms and virtual contexts: Research and practice. London: Equinox.

Leow, R. P. (1997). The effects of input enhancement and text length on adult L2 readers comprehension and intake in second language acquisition. Applied Language Learning, 8(2), 151-182.

Loschk-y, L., \& Bley-Vroman, R. (1993). Creating structure-based communication tasks for second language development. Working Papers in ESL, 2, 161-212.

McNicoll, J., \& Lee, J. (2011). Collaborative consciousness-raising tasks in EAL classrooms. English Teaching: Practice and Critique, 10(4), 127-138.

Morgan-Short, K., Sanz, C., Steinhauer, K., \& Ullman, M. (2010). Second language acquisition of gender agreement in explicit and implicit training conditions: An event-related potential study. Language Learning, 60 (1), 154-193.

Neupane, M. (2009). Processing instruction: An input based approach for teaching grammar. NELTA, 3, 29-41.

Retrieved from http:// nepjol.info/index.php/NELTA/article/download/3097/2215

Overstreet, M. (1998). Text enhancement and content familiarity: The focus of learner's attention. Spanish Applied

Linguistics, 2, 229-258.

Reinders, H., and R. Ellis. (2009). The effects of two types of positive enhanced input on intake and L2 acquisition.

In Ellis R. Loewen S. Erlam R. Philp J. Elder C. \& Reinders H. (Eds.), Multilingual matters, (pp.27-41). Clevedon:

Multilingual Matters.

Robinson, P. (1997). Generalizability and automaticity of second language learning under implicit, incidental, enhanced, and instructed conditions. Studies in Second Language Acquisition, 19(3), 223-47.

Rosa, E., \& O'Neill, M. (1998). Effects of stress and location on acoustic salience at the initial stages of Spanish L2 input processing. Spanish Applied Linguistics, 2, 24-52.

Salaberry, M. (1997). The role of input and output practice in second language acquisition. The Canadian Modern Language Review, 53, 422-451.

Sanz, C., \& Morgan-Short, K. (2004). Positive evidence vs. explicit rule presentation and explicit negative feedback: A computer-assisted study. Language Learning, 54, 35-78.

Scheffler, P. \& Cinciała, M. (2010). Explicit grammar rules and L2 acquisition. ELT Journal 1-11. Schmidt, R. (2001). Attention. In P. Robinson (Ed.), Cognition and second language instruction. (pp. 3-32). Cambridge: Cambridge University Press.

Sharwood Smith, M. (1991). Speaking to many minds: On the relevance of different types of language information for the L2 learner. Second Language Research, 7, 118-132.

Simard, D. (2009). Differential effects of textual enhancement formats on intake. System, 37, 124-135. Retrieved from http://dx.doi.org/10.1016/j.system.2008.06.005

Stafford, C.A., Bowden, H., \& Sanz, C. (2012). Optimizing language instruction: matters of explicitness, practice, and cue learning. Language Learning, 62(3), 741-768.

Sugiharto, P. (2006). Grammar consciousness-raising, research, theory, and application. Indonesian Journal of English Language Teaching, 2, 140-148.

Takimoto, M. (2012). The effects of explicit feedback and form-meaning processing on the development of pragmatic proficiency in consciousness-raising tasks. System, 34, 601-614.

Toth, P. D. (2006). Processing Instruction and a role for output in second language acquisition. Language Learning, 56,319-385.

Trahey, M., \& White, L. (1993). Positive evidence and pre-emption in the second language classroom. Studies in Second Language Acquisition, 15, 181-204.

VanPatten, B. (1996). Input processing and grammar instruction: Theory and research. Norwood, NJ: Ablex.

VanPatten, B. (2004). Processing instruction. Mahwah, NJ: Lawrence Erlbaum.

VanPatten, B., \& Cadierno, T. (1993a). Explicit instruction and input processing. Studies in Second Language Acquisition, 15, 225-243.

VanPatten, B., \& Cadierno, T. (1993b). Explicit instruction and input processing. Studies in Language Acquisition, 15, 225-243.

VanPatten, B., \& Oikkenon, S. (1996). Explanation vs. structured input in processing instruction. Studies in Second Language Acquisition, 18, 495-510. 
VanPatten, B., \& Uludag, O. (2011). Transfer of training and processing instruction: From input to output. System, 39, 44-53.

VanPatten, B., \& Wong, W. (2004). Processing instruction and the French causative: A replication. In B. VanPatten (Ed.), Processing instruction: Theory, research, and commentary (pp. 9-117). Mahwah, NJ: Lawrence Erlbaum Associates.

Wong, W. (2004). Processing instruction in French: The roles of explicit information and structured input. In B. VanPatten (Ed.), Processing instruction: Theory, research, and commentary (pp. 187-205). Mahwah, NJ: Erlbaum. Yip, V. (1994). Grammar consciousness-raising and learnability. In Odlin, T. (Ed.), Perspective on pedagogical grammar (pp. 132-147). Cambridge: Cambridge University Press.

Appendix (A): Samples of the structured input activities

Pratt Taylor is a high school math teacher. Last night he had a very strange call. Below are some incomplete sentences about that happening.

\section{Activity1}

Read these incomplete sentences and choose the correct item.

1.The phone rang at Pratt Taylor's house and he wondered...

a) what time it was

b) what time was it

2. Pratt answered the phone groggily but he was not sure

a) who the speaker was

b) who was the speaker

\section{Activity 2}

Read these short conversations and choose the best summary for them.

1. Pratt: I don't know what I should do.

Martin: You should pay the bail money.

a) Pratt didn’t know how he can help Martin. b) "What should I do? " Pratt asks.

2. Martin: I'll talk about it later.

Pratt: Ok, but you should tell the truth.

a) "Do you know what you the truth is? " Pratt asks. b) Pratt doesn't know what the truth is.

\section{Activity 3}

Listen to each sentence and select a sentence that match what you hear.

1. $\square$ Pratt is not sure what he is getting himself into.

口 "Please tell me what I am getting myself into?" Pratt asks

2. $\square$ "I don’t know how I should recognize your brother," Pratt says.

口 "Can you tell me how I should recognize your brother?" Pratt asks.

\section{Sentences heard by learners.}

1. What am I getting myself into?

2. How should I recognize your brother?

\section{Activity 4}

Each sentence below indicates the possibility of happening in your daily life. Have you ever had same experience or not?

1. I can't remember what my high school math teacher's name was.

\section{Same Different}

2. I didn't know what bail money was.

\section{Activity 5}

Now read the whole story and answer its questions. (the same reading comprehension used in the Appendix C without any boldfacing and underlining the target structure)

\section{Questions}

1. As used at the end of the story, which is the best antonym for hesitant?
a) comfortable
b) decisive
c) relaxed
d) secure 
2. Which best explains why Pratt decided to get the money for Martin?

a) Pratt had the money to give.

b) Pratt believed Martin was innocent.

c) Pratt had promised help many years ago.

d) Pratt feared Martin would hurt him if he did not comply.

Appendix (B): Samples of the Consciousness-Raising Tasks

Read the following passage carefully about Pratt Taylor's strange call and answer its questions (the same passage and questions used in Appendix A). You need to work with your partners to complete the table.

\begin{tabular}{|l|c|c|c|}
\hline & Correct & Incorrect & $\begin{array}{c}\text { Explanation of the } \\
\text { sentences in Persian }\end{array}$ \\
\hline $\mathbf{1}$ & Pratt wondered what time it was. & & \\
\hline $\mathbf{2}$ & & "Pratt was not sure who was the speaker." & \\
\hline $\mathbf{3}$ & $\begin{array}{c}\text { "Can you tell me where I should } \\
\text { bring the money?" }\end{array}$ & $\begin{array}{c}\text { Pratt didn't know where was he after his } \\
\text { graduation. }\end{array}$ & \\
\hline $\mathbf{4}$ & & & \\
\hline
\end{tabular}

Appendix (C): Sample of the textual enhancement tasks Directions: Read the following passage carefully and pay attention to the bolds and underlined parts and work with your partners to answer the questions related to them.

Bail

The phone rang at Pratt Taylor's house. Pratt wondered what time it was. He looked at the alarm clock on the desk. It was 3:00 A.M. Then he answered the phone after the fourth ring. "Mr. Taylor. I need your help. "Pratt was not sure who the speaker was." Mr. Taylor!" the man said again "I am in jail."

Now Pratt recognized the voice. It belonged to a boy named Martin Hall. He couldn't remember when he was his student exactly but he was one of the most brilliant students he had ever taught. However, Pratt didn't know where he was after his graduation.

Now Pratt said, "Please tell me what happened," "Bail money," Martin answered. HE Martin needed one thousand dollars. He knew he could pay that money, but he was not sure what he was getting himself into. "Can you explain why you are in jail?" Pratt asked. But Martin wanted to talk about it later. Now, Pratt determined his decision. "Please tell me where I should bring the money?" he asked. "At Jessup in Maryland?" Martin answered. Pratt asked, "Do you know how I should find that place?" "My brother will come by your place in the morning. Please give him the money," Martin answered. Again Pratt wondered how he should recognize his brother. So he decided to find Jessup himself and asked "Do you know exactly what time I should bring the money?" "At 8. A.M." Martin said. Upon hanging up the phone, Pratt was overcome by a dreadful feeling; his intuition told him that the decision to bail Martin out would be one that would vex him for a very, very long time.

Activity1

Comprehension Questions: (the same questions used after the passage in Appendix A)

Activity 2 (exactly the same items used in the first activity of Appendix A) 